\title{
Putting the personal into risk measurement: exploring the roles of psychological and sociological factors in the perception of risk in the water industry
}

\author{
$\underline{\text { Kosovac, A. }}{ }^{\text {a }}$ Davidson, B. ${ }^{a}$ and Malano, H. ${ }^{\text {b }}$ \\ ${ }^{a}$ School of Veterinary and Agricultural Sciences, The University of Melbourne, Melbourne, Australia \\ ${ }^{b}$ School of Infrastructure Engineering, The University of Melbourne, Melbourne, Australia \\ Email:Anna.Kosovac@unimelb.edu.au
}

\begin{abstract}
Risk measurement has predominantly utilised the technical and scientific approach to risk, developed in the 1950s and 1960s. This 'rational' and 'objective' approach to assessing risks has not been updated and is still widely used within the water industry. Furthermore, it has been cemented in risk management standards, and acts as the key model for risk assessments. Risk research in the last forty years has proposed alternate theories that are highly critical of the systematic, 'rational' approach of these old risk practices. This criticism stems from the lack of incorporating psychological, sociological and cultural risk elements in assessments, thus limiting the scope of how risks are actually perceived by assessors. Psychological approaches consider the risk assessor's own affiliations with the risk, based on experience and other psychological factors. Sociological theories, such as those proposed by Mary Douglas and Aaron Wildavsky, argue that the beliefs, or worldviews of the assessor more effectively describes how a risk will be evaluated.

In this paper an approach to test the extent technical risk approaches can be deemed 'rational' and 'objective' and whether psychological or cultural theories of risk may be more effectively describe how risks are actually evaluated, are highlighted. The water sector's existing risk processes are used to test these theories; however, this paper only covers the methods utilised, not the results obtained. The water industry is highly regulated, and also (in most cases) government-led, acting as a good candidate for assessment of risk processes. Water management is also becoming an ever more pertinent issue. In circumstances of declining supply and increased demand, risk assessments act as the decision-making tool in the gateway to implementing new projects. Therefore, whether risks are assessed comprehensively will have long-term ramifications in water management.
\end{abstract}

Keywords: Risk, water, assessment, sociology 
Kosovac, Davidson and Malano, Psychology, Sociology and Risk: compared to current risk practices, could these elements more comprehensively explain how risk is perceived in the water industry?

\section{INTRODUCTION}

The approaches to risk within the water public sector in Victoria are relatively consistent in being heavily based on the Australian Standards ISO31000 Risk Assessment document, with its focus on quantifying elements of risk. ISO31000 highlights a standard risk assessment approach, with the following elements: risk identification, analysis, evaluation and treatment (Council of Standards Australia, 2009, p. 14).

Identifying the risk involves generating 'a comprehensive list of risks based on those events that might create enhance, prevent, degrade, accelerate or delay the achievement of objectives' (Council of Standards Australia, 2009 , p. 17). The standards also highlight the inherent importance of not pursuing an opportunity. However, how this is implemented is not explored in the document. Following from this, the risk analysis process focuses on the consequences of the risks identified, as well as its corresponding likelihood. Quantifying this probability and likelihood, as defined by ISO3100, should be based on 'modelling the outcomes of an event or set of events... by extrapolation from experimental studies or available data.' (Council of Standards Australia, 2009, p. 18).

This begs the question of how likely it is that the risk assessor has access to this type of information, particularly for any new and unfamiliar projects, and to what extent assumptions are relied upon. Furthermore, this quantified-style of risk measurement does not account for psychological and cultural influences in its assessments, allowing subjective elements to go misunderstood (Kosovac, Davidson, Malano, \& Cook, 2017). This paper proposes a method of testing for the extent of these factors in risk assessment processes in the water industry in Melbourne.

\section{MANAGING RISK IN THE MELBOURNE WATER SECTOR: CURRENT APPROACHES}

ISO31000 underlies the overall risk process structure of all the Melbourne water authorities. The four water authorities assessed in this research are Melbourne Water, Yarra Valley Water, South East Water and City West Water, all located within metropolitan Melbourne, Australia. Melbourne Water is the bulk water supplier for the other three authorities, who then on-sell the water through to the customer. Melbourne Water, a public government owned body, manages and owns the large water infrastructure in Melbourne, such as larger water transfer lines, large treatment plants, and dams. The three smaller water authorities have set boundaries of control that do not overlap. They control smaller distribution lines, their own distribution zones, tanks, smaller treatment plants and also interact directly with customers in supplying their water and wastewater services. None of the three water retailers, Yarra Valley Water, City West Water or South East Water, are responsible for stormwater services. These tend to be managed jointly by Melbourne Water and local councils.

All water authorities take a prescriptive approach to managing their risk. They carry a version of a corporate risk matrix, highlighting risk consequences and their corresponding ratings. These risk categories are devised within the water authority, and hugely depend on the risk appetite of the organisation, which may differ slightly between each one. The risks facing water authorities are varied and broad in scope. They may range from water quality issues, technical failures, interruption of supply, through to political government distrust, negative media mentions and community backlash. Additionally, safety and financial risks also play a large role.

As per the standards, all water companies also rely on both the consequence of a risk and its likelihood, assessed by the risk assessor, often the project manager. This forms a key element of a business case in whether to proceed with a particular project. This type of risk process stems from the engineering/technical risk approach emphasised in the risk literature. The technical risk approach took hold in the 1950s, with Starr (Starr, 1969). The approach argues for an objectified, quantified approach to assessing a risk within a project, or merely an action. The theory sees risk as an objective reality that exists, underlining that should a 'rational' person assesses the risk, it should result in the one objective risk score regardless of the assessor. This process had already been in use in the engineering space prior to Starr's seminal work in 1969.

Risk analyses changed over time, with a Probabilistic Risk Assessment (PRA) approach in the 1970s (Bradbury, 1989, p. 382). Traditionally made up of a combination of two factors: probability and consequence, the key influential document in this risk approach was the "Reactor Nuclear Safety" study undertaken by the United States Nuclear Regulatory Commission, published in 1975 (United States Nuclear Regulatory Commission, 1975). It was the first major project to incorporate the PRA into its planning (Bradbury, 1989, p. 382). The risk in the report was given by the probability and magnitude of a range of different consequences, many related to the number of fatalities (United States Nuclear Regulatory Commission, 1975, pp. 13-39). The process carries a large scientific element to its approach, relying on data from testing procedures. As such, it represents a risk analysis process that is value-neutral with risk being treated as 'objective fact' (Bradbury, 382). 
Kosovac, Davidson and Malano, Psychology, Sociology and Risk: compared to current risk practices, could these elements more comprehensively explain how risk is perceived in the water industry?

The PRA approach assumes that people are rational beings, and thus an objective quantification of a risk can be realised. Kates and Kasperson (1983) argue that the popularity of the quantitative approaches to risk came about from two key motivations: increased public concern in technological risk, and also as a tool to be able to address the ever-challenging area of 'the acceptability of a risk' (Kates \& Kasperson, 1983, p. 7028).

This type of risk approach has been criticised in the literature for its rigid approach that ignores the nature of human beings as non-rational beings (Beck, 1992) (Self, 1975). Humans have been shown to act irrationally in situations, the extent of which changes between each individual. Additionally, it ignores the value-laden decision-making in risk analyses. As risk has become less about engineering and technology over the years, and more about incorporating elements of social behaviour, the traditional technical risk approach may not be entirely appropriate in this field (Bradbury, 1989, p. 383). This is further complicated through the 'apparent theoretical disarray' between behavioural scientists and risk managers, rendering it difficult to find an effective middle-ground (Rayner, 1992, p. 201).

\subsection{Psychological Risk Perceptions}

Paul Slovic criticises the technical risk approach for this very reason, citing how psychological affiliations to a risk will change how one perceives them (Paul Slovic, 1993). He argues that the risk score is devised not from the objective reality of a risk, but rather, from the risk assessor's perception of the risk (Paul Slovic, 1993). This perception will differ based on elements such as affect heuristics, the perception that one would place value in lowering the negative effects of a risk (afraid of loss) rather than highlight the potential benefits of the project (the potential gains from the action).

Slovic also theorises the psychometric responses to a risk, which ultimately is about the risk assessor's personal affiliation to the risk. For example, if an individual enjoys undertaking risky behaviour or has a positive experience associated with a particular course of action, they may rate the negative consequence of the risk as being lower than one who has only had a negative experience with that same course of action (Alhakami \& Slovic, 1994).

\subsection{Grid-Group Typology - cultural approaches}

Similarly, Mary Douglas and Aaron Wildavsky are equally as critical of a technical approach to risk (Douglas \& Wildavsky, 1982). Arguing from a cultural standpoint, they see risk as not being devoid of social conditioning, thus allowing elements of this constructivism to seep into the way the individual sees risk. Douglas takes this theory further through highlighting how an assessor's particular worldview will inform their risk choices (Douglas \& Wildavsky, 1982). She proposes four key worldviews based on the grid/group approach.

Mary Douglas found that there were key social groupings in this approach, and created a theory on the gridgroup typology (Douglas, 1996). She theorised that not only did it matter how people were grouped into associations and consortiums, but also whether these groupings were structured internally or not. Without a grouping, a social structure can still exist. This had created an arrangement similar to a Cartesian plane made up of grid on one axis, with group on the other. The following section further explores the definitions of grid/group and also the categories that are inherently created within the plane.

The group axis considers the extent to which an individual's life is absorbed by, and influenced by, group membership. This is an important element in understanding the boundaries of a group, how inclusive their membership may be, and also how an individual's own perceptions could be altered by their involvement in the group. A low group membership, or low group on the plane implies a higher level of individuality of a person (Douglas, 1996, p. viii).

Grid, as distinct from Group, describes the level of social structure. This social structure defines how individuals relate to one another, and their relationships. For example, in a low grid, people are less defined by a particular role, that you can meet one individual and their social status in reference to another person within that dimension will not vary.

The Cartesian plane made up of grid and group forms four distinct social groupings (Hierarchy, Egalitarianism, Individualism and Fatalism):

- $\quad$ High Group/High Grid = Hierarchy

- $\quad$ High Group/Low Grid = Egalitarianism

- $\quad$ Low Group/Low Grid = Individualism

- $\quad$ Low Group/ High Grid = Fatalism 
Kosovac, Davidson and Malano, Psychology, Sociology and Risk: compared to current risk practices, could these elements more comprehensively explain how risk is perceived in the water industry?

Douglas and Wildavsky further explore the grid-group approach, highlighting how adherence to a certain category carries with it a likelihood to treat risk in a particular manner, depending on the location on the plane (Douglas \& Wildavsky, 1982). For example, a fatalist may see risk as something that cannot be shifted or altered according to their own actions. That risk is essentially 'there' and 'not controllable'. They would accept decisions made by others in terms of risk acceptability, and feel that they have no power in whether they are exposed to the risk or not. In this way, a fatalist may respond differently to a risk than an individualist. The individualist, conversely sees risk as something that can be controlled to some extent, but all decisions as to the exposure to risk should be made by the individuals themselves, not by any other entity or group. For example, an individualist may see the choice to vaccinate as a right of their own, and therefore, the risk that is placed on them should only be as a result of their own decisions, not decisions made by others. This worldview encompasses, and is heavily based on personal choice.

\section{MEASURING AND ASSESSING DIFFERING CONSTRUCTIONS OF RISK}

This then leads into exploring these risk theories in the water sector, to determine whether there may be an approach that more accurately describes how one perceives the risk. As described above, the aim is to determine the reasons for one project proceeding whereas if undertaken by another assessor, it may have been deemed 'too risky'. Understanding this could provide key insight into which projects progress and which do not, in particular understanding why this is the case. It allows for the prospect to counter this, to not 'miss out' on opportunities merely because the project risk assessor carries certain psychological or cultural barriers to seeing the risk as being unacceptably high.

The key benefit of the technical risk approach pushed by proponents of the theory is the objective nature of the assessment. Ultimately arguing that taking a consequence and likelihood quantified risk approach, scores can be given to projects to objectively measure the risk that exists. If this is done as per the set process, then essentially, the 'objective risk reality' should be made apparent in these assessments regardless of who undertakes the assessment.

This paper highlights an approach to first measure the 'objective reality' of the technical risk approach through the means of a survey. The aim of this segment of the survey is to determine whether existing approaches to measuring risk in the water sector are objective.

\subsection{Technical Risk Approach Measurement}

Each participant is given a description of seven different water projects. Some of the projects will be familiar, for example, a water pipe renewal, others will be totally new; however all are completely fictional. Each participant is given a limited set of information with which to base their risk assessment. They are purposely provided with a standardised limited amount of information, requiring certain assumptions to be made, which is not unusual for water projects when assessing risk.

Following from this brief description, the participant is asked to devise a quantitative risk score (or rating) for each project, based on their organisation's risk process model (which they are ordinarily familiar with). All participants are provided with their organisation's risk framework. This framework is built on choosing a prevailing negative risk category (the risk the assessor deems to be the most prevalent for the proposed project), and gain a risk score or rating from its consequence and likelihood scores.

The analytical aspect of the research will involve the researcher comparing the risk scores between each risk assessor from each organisation to determine how 'objective' the risk process actually is. This will be comparing the 'variance' and standard deviation of each set of scores per project to assess the objectiveness of the technical risk approach posed by each organisation. Should this variance be too high, the process cannot then be concluded to be a completely objectified, rational approach. This could point to some other potential factors to explain this variance in scores. Two of these will be tested as part of the research-psychological affiliations to the risk as well as the cultural worldview affiliation.

\subsection{Psychological Risk Affiliation Methodology}

In order to understand the difference in scores between assessors, we will first test any psychological affiliations to the risk that the participant may have. These are highlighted as risk attributes within Slovic's study in 1985 on Characterising Perceived Risk (P. Slovic, Fischhoff, \& Lichtenstein, 1985). These attributes are:

- Voluntariness of Risk - whether people who are faced with this risk, do so voluntarily. 
Kosovac, Davidson and Malano, Psychology, Sociology and Risk: compared to current risk practices, could these elements more comprehensively explain how risk is perceived in the water industry?

- Immediacy of Effect - whether death occurs immediately, or whether it is delayed (for example, radiation.)

- Knowledge about Risk (to those exposed) - to what extent people who are exposed to risk, know about the risk.

- Knowledge about Risk (to Scientists) - to what extent does the assessor believe that experts understand the risks.

- Control over Risk - whether those exposed to the risk can effectively avoid death or injury through choice, and personal skill.

- Newness - determines how new the assessor feels this risk is (as opposed to old and familiar).

- Chronic-Catastrophic - whether the risk kills people one at a time or all at once (assuming that death is an outcome).

- Common - Dread - assesses how much dread is associated with the risk.

- Severity of Consequence - the likelihood of a risk being fatal.

- Unfairness - assessing how fair the risk seems to the assessor (does it affect all people fairly).

The above attributes are presented as statements, asking the participant to highlight their response through a 7point Likert scale. The scale allows for a mid-point 'neutral' option in this case.

The key difference in this study to others (such as Paul Slovic (1992) and Fischhoff, Slovic, Lichtenstein, Read, and Combs (1978)) is comparing the psychological risk affiliations through to the quantitative risk scores given. In particular, to determine whether there is a type of risk attribute that is likely to produce higher risk scores over other risk attributes. This could result in the one overarching risk attribute that tends to indicate higher risk scores, or a combination of a few risk attributes that highlights this. In this section of the research, the aim is to determine to what extent a particular psychological affiliation produces a higher risk perception in the water industry.

\subsection{Cultural Grid-Group Risk Methodology}

The final test is to see whether there exists a correlation between a particular worldview (the grid-group segment a participant adheres to) and the likelihood of gaining higher risk scores in certain areas/projects. This further investigates how an individual's risk perception will be informed by their cultural worldviews.

In measuring worldviews, Karl Dake is one of the key proponents in the area of cultural theory measurement (Dake, 1992). His methodology was utilised by various studies (Ellis \& Thompson, 1997) (Peters \& Slovic, 1996) however was criticised because of the reliability of the scale used. Studies such as Marris, Langford, and O'Riordan (1998) and Sjoberg (1998), concluded that Dake's use of a single scale to measure each cultural worldview performed poorly in internal validity for tests like Cronbach's alpha. Kahan (2008) drawing from other recent studies in addition to Dake's approach (Jenkins-Smith \& Herron, 2009) instead changed the methodology slightly to incorporate a dual scale system, measuring each worldview category on separate ends of the scale. Participants then indicate to what extent they agree or disagree with the statement on either a sixpoint or four-point Likert scale. In this instance, the study has incorporated a six-point scale. The responses then indicate towards a certain scale on the line of hierarchy - egalitarian, and individualism-communitarianism scores, placing the individual within a particular cultural worldview group (Jenkins-Smith \& Herron, 2009, p. 731).

After allocating each respondent into one of four worldviews (Hierarchy, Egalitarianism, Individualism or Fatalism), the next analysis is to determine whether there is a significant correlation between the cultural worldview a respondent has, to the way that they perceive a risk for water projects. Each grid-group is assessed separately, together with each respondent's corresponding risk scores to assess whether there may be a link between how they perceive the world and how they ranked each project. This can also be assessed per project to highlight whether there are specific elements in the project that adhere to a particular worldview. This may promote understanding in how a cultural worldview may inform a risk judgement, providing the opportunity for a reassessment of existing risk processes to ensure these are aligned with the corporate risk appetite.

\subsection{Implementation}

Any changes to existing risk processes within water authorities will be highly dependent upon the outcomes of the study (i.e. to what extent can any variation in risk scores be explained by behavioural or sociological factors). Should the hypothesis, (that risk is subjective and dependent upon individual psychological and 
Kosovac, Davidson and Malano, Psychology, Sociology and Risk: compared to current risk practices, could these elements more comprehensively explain how risk is perceived in the water industry?

sociological factors), prove true, it can allow for water authorities to alter its risk assessment process in line with the results. For example, should the results of the study indicate a high correlation between a particular worldview, and risk scores, this can be implemented through a weightings-based approach. The worldview of the risk assessor would result in a weighting added to their risk score that is in line with the organisation's predefined risk appetite statement. Similarly with the psychometric risk testing. If a particular risk attribute indicates higher risk scores that lies outside the pre-defined risk appetite statement, this can be added as part of future risk assessments, with a similar weightings-based approach attached to the scores. For example, if a higher score on a 'dread' rating on projects leads to higher risk scores, and this falls outside of the company's risk appetite, a numerical weighting can be placed on the score to counter the psychological effect of the attribute. The actual implementation element of the research, therefore, will rely heavily on the research results of the study.

\section{CONCLUSION}

Since before Starr's seminal work on Social Value in Risk, risk analysis approaches have been utilised in the engineering field. With the rise of Probabilistic Risk Assessments (PRA) in the 1970s, there has not been any significant changes to the way that risks are assessed today. This is despite risk literature flourishing in the space, and an increase in the interest in risk research presenting new ideas of managing risk. Additionally, much risk literature has been widely critical of the traditional, technical approaches to risk, citing that they cannot be objective, and cannot be devoid of value judgements. The psychological risk approaches, and cultural worldview approaches are two key risk theories that have provided compelling cases in explaining how one perceives a risk. Despite this, risk standards, and approaches have shifted very little in practice.

In the case of the public water sector in Melbourne, there is still an adherence to technical, engineering style approaches to risk, based in quantitatively measuring consequence and likelihood to produce a final risk rating. The methodology within this paper highlighted some areas where these risk approaches can be tested, while also providing the opportunity to investigate alternative theories of risk, namely the psychological risk approach and cultural worldview theories.

Testing all three theories can provide further insight into the way that water professionals within Melbourne see risk while using this information to point to a greater understanding of how risk processes can be improved. As many public sector regulators and government departments, particularly in water, utilise similar risk processes, this study and methodological process can provide a pathway to understanding whether risks are assessed effectively, and ultimately, if these assessments fit within the set risk appetite of the organisation.

\section{REFERENCES}

Alhakami, A. S., \& Slovic, P. (1994). A psychological study of the inverse relationship between perceived risk and perceived benefit. Risk Analysis: An Official Publication Of The Society For Risk Analysis, 14(6), 1085-1096.

Beck, U. (1992). Risk society: towards a new modernity. London: Sage Publications.

Bradbury, J. A. (1989). The Policy Implications of Differing Concepts of Risk. Science, Technology, \& Human Values(4), 380.

Council of Standards Australia. (2009). Risk Management - Principles and Guidelines (Vol. AS/NZS ISO 31000:2009). Sydney: Standards Australia.

Dake, K. (1992). Myths of Nature: Culture and the Social Construction of Risk. Journal of Social Issues, 48(4), 21-37.

Douglas, M. (1996). Natural symbols. [electronic resource] : explorations in cosmology: London ; New York : Routledge, 1996.

Douglas, M., \& Wildavsky, A. B. (1982). Risk and culture. [electronic resource] : an essay on the selection of technological and environmental dangers: Berkeley : University of California Press, 1982 (1983 printing).

Ellis, R. J., \& Thompson, F. (1997). Culture and the Environment in the Pacific Northwest. American Political Science Review, 91(04), 885-897. doi:doi:10.2307/2952171

Fischhoff, B., Slovic, P., Lichtenstein, S., Read, S., \& Combs, B. (1978). How Safe Is Safe Enough Psychometric Study Of Attitudes Towards Technological Risks And Benefits. Policy Sciences, 9(2), 127-152. doi:10.1007/bf00143739

Jenkins-Smith, H., \& Herron, K. (2009). Rock and a Hard Place: public wilingness to trade civil rights and liberties for greater security. Political Policy, 37(5), 1095-1129.

Kahan, D. M. (2008). Cultural Cognition as a Conceptin of the Cultural Theory of Risk. In S. Roeser (Ed.), Handbook of Risk Theory. 
Kosovac, Davidson and Malano, Psychology, Sociology and Risk: compared to current risk practices, could these elements more comprehensively explain how risk is perceived in the water industry?

Kates, R. W., \& Kasperson, J. X. (1983). Comparative Risk Analysis of Technological Hazards (A Review). Proceedings of the National Academy of Sciences of the United States of America(22), 7027.

Kosovac, A., Davidson, B., Malano, H., \& Cook, J. (2017). The Varied Nature of Risk and Considerations for the Water Industry: A Review of the Literature. Environment and Natural Resources Research, 7(2), $80-86$.

Marris, C., Langford, I., \& O'Riordan, T. (1998). A Quantitative Test of the Cultural Theory of Risk Perceptions: comparison with the psychometric paradigm. Risk Analysis, 18(5), 635-647.

Peters, E., \& Slovic, P. (1996). The Role of Affect and Worldviews as Orienting Dispositions in the Perception and Acceptance of Nuclear Power1. Journal of Applied Social Psychology, 26(16), 1427-1453. doi:10.1111/j.1559-1816.1996.tb00079.x

Rayner, S. (1992). Cultural Theory and Risk Analysis. In S. Krimsky \& D. Golding (Eds.), Social Theories of Risk (pp. 83-116). Westport, CT: Praeger Publishers.

Self, P. (1975). Econocrats and the policy process : the politics and philosophy of cost-benefit analysis. London: Macmillan.

Sjoberg, L. (1998). Explaining risk perception: an empirical evaluation in cultural theory. In R. Lofstedt \& L. J. Frewer (Eds.), The Earthscan Reader in Risk and Modern Society (Vol. 2, pp. 115-132). London: Earthscan.

Slovic, P. (1992). Perception of Risk. In S. Krimsky \& D. Golding (Eds.), Social Theories of Risk (pp. 117153). Westport, CT: Praeger Publisher.

Slovic, P. (1993). Perceived risk, trust, and democracy. Risk Analysis: An International Journal, 675.

Slovic, P., Fischhoff, B., \& Lichtenstein, S. (1985). Characterising Perceived Risk. In R. W. Kates, C. Hohenemser, \& J. X. Kasperson (Eds.), Perilous Progress: Managing the Hazards of Technology (pp. 91-125). Boulder, CO: Westview.

Starr, C. (1969). Social Benefit versus Technological Risk. Science, 165, 1232-1238.

United States Nuclear Regulatory Commission. (1975). Reactor Safety Study: An Assessment of Accident Risks in U.S. commercial Nuclear Power Plants. Retrieved from Washington: 